\title{
Integração lavoura e pecuária: o estado da arte e inovações tecnológicas
}

\author{
Manuel Claudio Motta Macedo' \\ ${ }^{1}$ Embrapa Gado de Corte, Bolsista do CNPq. EMBRAPA- Gado de Corte, Caixa Postal 154, 79002-970, Campo Grande, MS.
}

RESUMO - Sustentabilidade é tema atual e cada vez mais discutido no desenvolvimento agropecuário do Brasil. Este tem experimentado um grande desenvolvimento tecnológico e produtivo no agronegócio, ampliando as exportações, a renda dos produtores, a oferta de alimentos com melhor qualidade, e menor custo aos consumidores. No entanto, dois aspectos chamam a atenção quando se analisa sustentabilidade: o uso do solo com preparo excessivo e monocultivos, e a degradação das pastagens. O monocultivo e práticas culturais inadequadas têm causado perda de produtividade, degradação do solo e dos recursos naturais. Sistemas contínuos com monocultivos aumentam a ocorrência de pragas e doenças, tais como o percevejo castanho, nematóides e a ferrugem da soja, causando inúmeros prejuízos. A reversão desse quadro pode ser conseguida por meio de tecnologias como o sistema de plantio direto (SPD), que contempla não só o preparo mínimo do solo, mas também a prática de rotação de culturas, e os sistemas de integração lavoura-pecuária (SILPs). A utilização do SPD já representa mais de 60\% dos sistemas de plantio. A adoção deste em sua plenitude, nas diversas condições climáticas e edáficas, no entanto, é altamente dependente de culturas adequadas para a produção e manutenção de palha sobre o solo, para que o sistema seja eficiente e vantajoso. Várias culturas têm sido utilizadas nos SILPs, entre as quais: soja, milho, milheto, sorgo, nabo forrageiro, girassol, algodão e gramíneas forrageiras tropicais, principalmente as braquiárias, consorciadas ou não. Os SILPs são alternativas para a recuperação de pastagens degradadas, e para a agricultura anual, melhorando a produção de palha para o SPD, as propriedades químicas, físicas e biológicas do solo, assim como, a utilização de equipamentos, a renda e o emprego no campo. Neste trabalho é feita uma apresentação do entendimento compreensivo dos SILPs, a evolução das pesquisas, resultados já alcançados, e considerações sobre o futuro.

Palavras-chave: Brachiaria, estoque de carbono, lavoura-pecuária, macrofauna, qualidade do solo, SILPs, sustentabilidade

\section{Crop and livestock integration: the state of the art and the near future}

\begin{abstract}
Sustainability is an actual theme and very present in all discussion in the tropical agriculture world, including Brazil. This country experienced high taxes of development in agribusiness, increasing exportation trading, producing foods of better quality and raising incoming rates of farmers. However, two mains aspects call the attention in respect to sustainability: excessive soil preparation with monoculture of annual crops and pasture degradation. These situations have brought losses in crop and livestock yields, increased soil degradation and collapse of natural resources. Continuous cropping of monoculture accelerates attacks of insects and diseases, specially the ones related to soil interactions. Technologies such as minimum tillage, crop rotation and crop-livestock integration can alleviate these problems and drive agriculture to sustainability. Minimum tillage has increase to more than $60 \%$ of soil tillage usage in Brazil. Adoption of this system in large scale, covering more regions, with different clime and soil, is highly dependent of crops that produce high amounts of residues and straw for better soil coverage. Crop-livestock integrated systems (CLIS) have been cultivated with many crops, such as: soybeans, corn, pearl millet, sorghum, cotton, sunflower, etc. and especially perennial tropical grasses as Brachiaria spp, intercropped or not. CLIS can be one important alternative to pasture recuperation and improvement of annual crops. They increase straw to minimum tillage systems, improve soil chemical, physical and biological properties, and better use of equipments, farmers income, and jobs in rural area. This paper analyze the state of the art in CLIS research, later results, and bring some considerations for the near the future of CLIS in Brazil.
\end{abstract}

Key Words: Brachiaria, carbon stock, CLIS, crop-livestock integration, macrofauna, soil quality, sustainability

\section{Introdução}

Temas como: exploração racional, exploração ambientalmente correta, sustentabilidade da produção, mecanismos de desenvolvimento limpo (MDL) são atuais e cada vez mais discutidos no desenvolvimento agropecuário do Brasil. O País tem experimentado um grande desenvolvimento tecnológico e produtivo no agronegócio, ampliando suas exportações e a renda dos produtores. Em que pese situações conjunturais de preços de commodities, 
insumos e produtos agrícolas com crises em algumas cadeias produtivas e categorias de produtores, é inegável o avanço da agropecuária no Brasil.

Dois grandes aspectos chamam a atenção quando se discute sustentabilidade da produção agrícola: o uso do solo com a agricultura tradicional, com preparo contínuo do solo, e a degradação das pastagens.

O monocultivo e práticas culturais inadequadas na agricultura, como o preparo tradicional do solo com contínuas ações de grades, têm causado queda na produtividade, degradação do solo e dos recursos naturais. Sistemas contínuos de monocultivos, por sua vez, aumentam a ocorrência de pragas e doenças, tais como o percevejo castanho da soja, o cancro da haste, o nematóide das galhas, e o nematóide do cisto com inúmeros prejuízos à sojicultura (Yorinori et al., 1993) e mais recentemente a ferrugem da soja.

O emprego excessivo de grades no preparo de solo tem sido uma das causas de degradação das propriedades físicas do solo, com camadas pulverizadas na superfície, estrutura comprometida, perdas de solo por erosão, e selamento superficial, como demonstrado por Denardin (1984) e Salton et al. (2005), no Mato Grosso do Sul. Outro problema do monocultivo associado ao mau manejo do solo é a concentração da fertilidade nas camadas superiores. Nessas condições, a saturação por bases é excessivamente alta, causando deficiência de micronutrientes, como o manganês na soja. A distribuição das raízes no perfil do solo fica também concentrada na superfície, tornando a cultura mais vulnerável aos veranicos.

A produção animal, sobretudo a de bovinos de corte e de leite no Brasil, é realizada principalmente em pastagens. Os sistemas extensivos de exploração ainda predominam sobre os demais, e as pastagens utilizadas podem ser nativas ou cultivadas. As gramíneas forrageiras cultivadas mais importantes em uso foram introduzidas da África e pertencem, em sua maioria, aos gêneros Brachiaria, Panicum e Andropogon (Andrade, 1994; Macedo \& Zimmer, 2007). Somente na região dos Cerrados avalia-se em 49,5 milhões de ha de pastagens cultivadas em uma área total de 208 milhões (Sano et al., 2001). Esta região é responsável por cerca de $50 \%$ da produção de carne do País (Macedo \& Zimmer, 2007).

Os solos ocupados por pastagens em geral são marginais quando comparados àqueles usados pela agricultura de grãos. Estes solos apresentam problemas de fertilidade natural, acidez, topografia, pedregosidade ou limitações de drenagem (Adamoli et al., 1986). Os solos de melhor aptidão agrícola são ocupados pelas lavouras anuais de grãos ou as de grande valor industrial para a produção de óleo, fibras, resinas, açúcar, etc. Dessa forma, é de se esperar que as áreas para exploração de bovinos de corte apresentem problemas de produtividade e de sustentabilidade da produção.

A degradação das pastagens é o fator mais importante, na atualidade, que compromete a sustentabilidade da produção animal, e pode ser explicada como um processo dinâmico de degeneração ou de queda relativa da produtividade (Macedo \& Zimmer, 1993; Zimmer et al. 1994; Macedo, 1999, 2000, 2001a). Dentre os fatores mais importantes relacionados com a degradação das pastagens destacam-se o manejo animal inadequado e a falta de reposição de nutrientes. A lotação animal excessiva, sem os ajustes para uma adequada capacidade de suporte, e a ausência de adubação de manutenção têm sido os aceleradores do processo de degradação.

A reversão desses quadros de queda da sustentabilidade da produção tem sido observada pela utilização de tecnologias importantes como o sistema de plantio direto (SPD), que contempla não só o preparo mínimo do solo, mas também a prática de rotação de culturas, e os sistemas de integração lavoura-pecuária (SILPs).

A utilização do SPD é uma tecnologia crescente, sendo que em 2003 na região dos Cerrados, segundo Duarte et al. (2006), já representava 40,78\% dos sistemas de plantio. Acredita-se que esse porcentual já tenha ultrapassado os 65\% em 2008/2009. O grande avanço se deu pelas vantagens comparativas entre o SPD e os sistemas tradicionais, em termos agronômicos, econômicos e ambientais. A adoção do SPD em sua plenitude, nas diversas condições climáticas e edáficas, no entanto, é altamente dependente de culturas adequadas para a produção e manutenção de palha sobre o solo, para que o sistema seja eficiente e vantajoso. Várias culturas têm sido utilizadas e testadas para cobertura de solo, rotação, e pastejo no outono-inverno, e entre as mais promissoras estão: o milho, o milheto, o sorgo granífero e o forrageiro,o nabo forrageiro e as gramíneas forrageiras tropicais, consorciadas ou não, sobretudo as braquiárias.

A degradação das pastagens, grandes extensões de área com monocultivo da soja no verão, a pressão social sobre a terra, dividas financeiras, preços de insumos e produtos, e competição global, vem exigindo, cada vez mais eficiência dos produtores. Nesse sentido, os sistemas de integração lavoura-pecuária (SILPs), podem ser promissores para atender tanto as dificuldades da pecuária, como alternativa de recuperação de pastagens degradadas, como para a agricultura anual e o SPD, visando à produção de palha, melhoria das propriedades do solo e utilização plena 
de equipamentos, empregos e aumento de renda no campo.

Pretende-se neste trabalho oferecer uma apresentação do entendimento compreensivo dos SILPs, sua evolução, alguns importantes resultados já conseguidos pela pesquisa e considerações para o futuro.

\section{Sistemas de integração lavoura-pecuária-SILPs}

O plantio de lavouras de grãos, como o milho e o arroz, e pastagens anuais de milheto ou sorgo forrageiro, tem sido há algum tempo uma prática cultural muito utilizada no processo de recuperação ou renovação de pastagens cultivadas. O plantio do milho com o capim colonião, semeado em cobertura é um exemplo antigo dessa atividade, préutilização do sistema plantio direto e simultâneo. O uso eventual dessas atividades pelo próprio produtor, ou através de parcerias ou arrendamentos, pode ser apenas uma estratégia para diminuir custos e retornar rapidamente para a atividade principal da produção animal (Macedo \& Zimmer, 1990, 1993; Kluthcouski, et al. 1991; Zimmer, et al., 1999; Macedo \& Zimmer, 2007).

Mais recentemente tem crescido uma alternativa muito eficiente, porém mais complexa, de manutenção da produtividade e de recuperação/renovação indireta de pastagens que é a integração lavoura-pecuária, na qual a introdução de lavouras não é eventual, mas parte constante de um sistema de produção de grãos e de produção animal que interagem e se completam em aspectos, do manejo, da fertilidade, da física e da biologia do solo, aumentado a renda dos produtores e trazendo progresso social ao campo.

Esse sistema permite uso mais racional de insumos, máquinas e mão-de-obra na propriedade agrícola, além de diversificar a produção e o fluxo de caixa dos produtores. Evidentemente que alguns requisitos são necessários para implementar o sistema, tais como, máquinas e implementos agrícolas mais diversificados, infra-estrutura de estradas e armazéns, mão-de-obra qualificada, domínio da tecnologia de lavouras anuais e pecuária, e conhecimento mais apurado do mercado agropecuário. A integração lavoura-pecuária permite sistemas de exploração em esquemas de rotação, onde se alternam anos ou períodos de pecuária com a produção de grãos ou fibras, utilização de produtos e subprodutos na alimentação animal, etc.

Uma definição consensual de integração lavourapecuária proposta por pesquisadores da Embrapa Gado de Corte, Embrapa Cerrados, Embrapa Milho e Sorgo e Embrapa Arroz e Feijão, que trabalham com SILPs seria a seguinte: “ Integração lavoura-pecuária são sistemas produtivos de grãos, fibras, carne, leite, lã, e outros, realizados na mesma área, em plantio simultâneo, seqüencial ou rotacionado, onde se objetiva maximizar a utilização dos ciclos biológicos das plantas, animais, e seus respectivos resíduos, aproveitar efeitos residuais de corretivos e fertilizantes, minimizar e otimizar a utilização de agroquímicos, aumentar a eficiência no uso de máquinas, equipamentos e mão-de-obra, gerar emprego e renda, melhorar as condições sociais no meio rural, diminuir impactos ao meio ambiente, visando a sustentabilidade'.

A integração lavoura-pecuária já é praticada há anos, de forma plena ou eventual, em muitos países. A utilização de resíduos de culturas na alimentação dos animais ou o pastejo das restevas de lavouras, por exemplo, são práticas freqüentes em uso em várias regiões do Brasil.

A integração lavoura-pastagem diverge de certa forma da integração lavoura-pecuária, quando se considera no processo como um todo, as interações efetivas que são realizadas na mesma área, entre produção de cultivos anuais e produção animal, sobretudo com os efeitos acumulados no tempo, que cada componente pode exercer sobre o outro. Por outro lado, também há casos em que alguns produtores fazem uso da lavoura e da pecuária na mesma propriedade, mas não necessariamente na mesma área, utilizando locais diferentes para a produção animal e a de culturas anuais. Estas entram com seus grãos ou sub-produtos na alimentação animal, mas os efeitos de rotação ou de resíduos que cada componente oferece ao outro não são utilizados.

A preocupação com o conhecimento da integração de sistemas de pastagem e lavouras motivou vários estudos. Na Austrália, White et al. (1978), numa revisão sobre os sistemas de uso do solo com pastagens e lavouras, discorreram sobre a necessidade de se aumentar o uso e a eficiência desses sistemas para uma melhor utilização da água e do nitrogênio. Os autores citam Donald (1964), o qual explica a evolução da produtividade do trigo na Austrália no período de 1880 a 1960 . Esse autor conclui que houve uma fase de queda na fertilidade do solo, entre 1880 e 1920 , por falta de reposição de nutrientes, com conseqüente queda na produtividade. Após esse período houve uma tendência à estabilização entre 1920-1960, com a introdução de novas cultivares, aplicação de superfosfato e pousio. A produtividade a partir dessa fase, segundo Donald, só teria condições de aumentar com a utilização de novas técnicas de plantio e mecanização, introdução de nitrogênio por leguminosas e sistemas de rotação (lavoura-pastagem).

A literatura a respeito da integração lavoura-pecuária de outros países mostra pontos positivos ao meio ambiente com a utilização desse sistema. Existem melhorias de ordem biológica, como a quebra do ciclo de pragas e doenças e aumento da atividade biológica do solo. 
Do ponto de vista das propriedades físicas e químicas do solo, há uma melhoria na fertilidade, pela ciclagem dos nutrientes e eficiência no uso de fertilizantes, em função das diferentes necessidades das culturas em rotação. As alterações nas propriedades físicas têm sido no aumento da estabilidade dos agregados, diminuição da densidade aparente, da compactação, e no aumento da taxa de infiltração de água.

Poucos experimentos de longa duração em ecossistemas tropicais e subtropicais têm sido relatados, alguns dos quais na Austrália e no Uruguai. Elliot \& Jardine (1972), no Sudoeste da Austrália, mostraram as vantagens da integração pastagem-lavoura sobre a produtividade do trigo por 29 anos, entre 1940 e 1968. Em sistemas de plantio contínuo de trigo, trigo-cevada, trigo- aveia, trigo-pasto e trigo-pasto-pasto, a inclusão da pastagem na rotação sempre proporcionou aumento da produtividade. O plantio contínuo de trigo foi menos produtivo no tempo.

Greenland (1971) em estudo de rotação semelhante, também na Austrália (1925-1963), cita que o nitrogênio armazenado ao longo dos anos pela inclusão de pastagens de gramíneas teve um efeito positivo e direto na produção do trigo quando este foi plantado em sucessão.

Um experimento de sistemas de rotação lavourapastagem bastante interessante vem sendo conduzido na Estação Experimental de La Estanzuela, no Uruguai, desde 1963. Resultados publicados por Rosello (1992), para o período de 1964-1990, mostram que a relação C/N aumentou cerca de $2 \%$ no tratamento lavoura contínua, causado pela diminuição do $\mathrm{N}$ - total, principalmente quando leguminosas não são plantadas em rotação.

Moron \& Kiehl (1992) nesse mesmo projeto, estudaram a dinâmica do fósforo. As principais perdas ou saídas de $\mathrm{P}$ teriam sido pela erosão e extração pelas culturas. De acordo com o balanço do P-total, o sistema "agricultura- pastagem" foi o mais positivo, seguido do sistema "agricultura contínua com fertilização". Prechac (1992) concluiu que quanto a várias propriedades físicas, o solo se degrada na lavoura contínua, mas se recupera com o plantio de pastagens de gramíneas e, se estas forem produtivas, influenciarão positivamente a produção de culturas anuais posteriores.

No Brasil já começam a surgir muitos resultados sobre SILPs, mas ainda poucos oriundos de experimentos de longa duração de rotação lavoura-pecuária.

\section{Evolução das pesquisas em integração lavoura-pecuária}

As pesquisas com integração lavoura-pecuária tiveram seu incremento desde 1990, quando foram instalados os primeiros experimentos de longa duração com SILPs, que temos conhecimento no Brasil, na Embrapa Cerrados
(Planaltina,DF), Gado de Corte (Campo Grande,MS) e Agropecuária do Oeste (Dourados, MS). Em seguida, temos as experiências em curso na Embrapa Arroz e Feijão (Santo Antonio de Goiás, GO) e Embrapa Milho e Sorgo (Sete Lagoas, MG). Outras experiências de longa duração provavelmente já tenham começado em outras localidades. A maioria dos experimentos que se referem à integração lavoura-pecuária são pontuais ou de curta duração, com períodos que variam de 2 a 4 anos, e nem sempre, enfatizam de forma integrada os dois componentes.

As dificuldades para a realização dessas pesquisas estão relacionadas principalmente ao custo, pois os experimentos são dispendiosos, exigem muitos animais, cerca, cochos, tanques de água, conservação de solo e tamanhos de parcelas que nem sempre estão disponíveis em estações experimentais, ou quando em propriedades de particulares, estes não têm interesse em patrocinar ações que demandam resultados que podem demorar cinco ou mais anos.

O plantio simultâneo de culturas anuais com pastagens

Este sistema de plantio é o mais estudado em trabalhos de pesquisa sobre SILPs e foi aquele que deu um grande estímulo para o início de adoção dos mesmos.

\section{Sistema Barreirão}

Segundo Cobucci et al. (2007), em 1991 foi lançado o Sistema Barreirão como uma alternativa para formação de pastagens em novas áreas e recuperação e/ou renovação de pastagens degradadas. Este é um sistema que utiliza o plantio simultâneo de culturas anuais com forrageiras e tem como objetivo principal a recuperação/renovação de pastagens degradadas. Sua criação tinha como propósito reduzir custos na formação e/ou recuperação das pastagens. As práticas que compõem o Sistema Barreirão, no entanto, fundamentam-se na possibilidade de redução de riscos climáticos inerentes à cultura, que no início centrava-se no arroz, e na correção, pelo menos parcial, das limitações físico-químicas do solo. O maior benefício do Sistema Barreirão foi em um primeiro momento o de incentivar os produtores para a necessidade de se recuperar/renovar pastagens degradadas e posteriormente para as vantagens da integração lavoura-pecuária.

Durante os períodos de 1987/88 e de 1990/94, segundo Cobucci et al. (2007) foram implantadas e/ou monitoradas 81 unidades de demonstração e/ou lavouras do Sistema Barreirão, em sete Estados da Federação (GO, MT, MS, TO, MG, SP e BA). Os rendimentos obtidos variaram de 600 a $3.415 \mathrm{~kg} \mathrm{ha}^{-1}$ para o arroz de terras altas, e de 2.100 a 7.430 $\mathrm{kg} \mathrm{ha}^{-1}$ para o milho. As médias de rendimento, por hectare, foram: para o arroz 33,5 sacas de $60 \mathrm{~kg}$ e para o milho 61,5 
sacas de $60 \mathrm{~kg}$ (Tabela 1). Nenhuma das lavouras do Sistema Barreirão, segundo os autores, sofreu perda total devido à má distribuição das chuvas.

As observações sobre as vantagens do Sistema Barreirão descrita pelos autores eram de que: (i) as culturas anuais consorciadas raramente eram atacadas por doenças ou pragas; (ii) não havia necessidade de se controlar plantas daninhas, graças ao ambiente "pastagem degradada" e ao manejo do solo, utilizando a técnica da aração (profunda) invertida (Oliveira et al., 1996), e; (iv) havia um controle altamente eficiente de cupins de montículo até o terceiro ano após a recuperação/renovação da pastagem.

Cobucci et al. (2007) descrevem também que os autores concluíram que: (i) a exploração da pecuária com pasto recuperado pelo Sistema Barreirão é uma atividade economicamente lucrativa devido à receita gerada pela venda dos grãos, que cobre parte dos custos da formação da pastagem; (ii) a recuperação/renovação de pastagem em consórcio com o milho é a melhor alternativa, desde que se obtenha produtividade do milho em torno da média do Sistema Barreirão (3.600 kg ha'-1).

Tabela 1 - Produtividades de arroz de terras altas e de milho obtidas em unidades demonstrativas do Sistema Barreirão, em quatro safras, em municípios de sete Estados da Federação

\begin{tabular}{llllrr}
\hline Safra & Cultura & Locais & \multicolumn{3}{c}{ Produtividade $\left(\mathrm{kg} \mathrm{ha}^{-1}\right)$} \\
\cline { 4 - 6 } & & & Média & Máxima & Mínima \\
\hline $1987 / 88$ & Arroz & $5^{1}$ & 2.063 & 2.654 & 1.415 \\
$1990 / 91$ & Arroz & $11^{2}$ & 2.040 & 2.588 & 990 \\
$1991 / 92$ & Arroz & $15^{3}$ & 2.280 & 3.200 & 1.100 \\
$1992 / 93$ & Arroz & $8^{4}$ & 1.860 & 2.160 & 1.440 \\
$1992 / 93$ & Milho & $3^{5}$ & 4.020 & 5.520 & 3.180 \\
$1993 / 94$ & Arroz & $23^{6}$ & 1.800 & 3.415 & 600 \\
$1993 / 94$ & Milho & $16^{7}$ & 3.360 & 7.430 & 2.100 \\
\hline
\end{tabular}

${ }^{1} \mathrm{GO}$ e $\mathrm{MT} ;{ }^{2} \mathrm{GO} ;{ }^{3} \mathrm{GO}, \mathrm{MT}, \mathrm{MG}, \mathrm{TO}, \mathrm{MS} ;{ }^{4} \mathrm{GO}, \mathrm{MT}, \mathrm{MG} ;{ }^{5} \mathrm{GO} ;{ }^{6} \mathrm{GO}, \mathrm{SP}, \mathrm{MS}, \mathrm{MG}$, BA, TO ${ }^{7} \mathrm{SP}, \mathrm{MS}, \mathrm{GO}, \mathrm{MT}, \mathrm{MG}$.

Fonte: Cobucci et al. (2007).
Yokoyama et al. (1998) avaliaram os impactos econômicos decorrentes da adoção do Sistema Barreirão.A tecnologia, além de possibilitar rendimentos médios superiores à média nacional (cerca de $1,7 \mathrm{t} \mathrm{ha}^{-1} \mathrm{e} 2,0 \mathrm{t}$ ha ${ }^{-1}$ para o arroz de terras altas e milho, respectivamente), reduziu drasticamente os riscos de perdas por estiagem (Tabela 2).

\section{Sistema Santa Fé}

O Sistema Santa Fé, segundo Cobucci et al. (2007), consiste na produção consorciada de culturas anuais com forrageiras tropicais, em sistema de plantio direto ou convencional, em áreas de lavoura, com solo parcial ou devidamente corrigido, objetivando produzir forragem na entressafra e/ou palhada para o sistema plantio direto no ano agrícola subseqüente. As culturas utilizadas no sistema são: milho, milheto, sorgo, arroz, soja e girassol, dentre outras. Com relação às forrageiras, destacam-se aquelas do gênero Brachiaria.

Lançado por Kluthcouski et al. (2000), este sistema teve início com o objetivo de ensilagem ou corte da B. brizantha, para fornecimento, no cocho, a animais confinados. A produção de forragem tem sido de aproximadamente $30 \mathrm{t} \mathrm{ha}^{-1}$ de matéria verde a cada 45 dias, sendo que em quatro cortes foi possível obter mais de $150 \mathrm{t} \mathrm{ha}^{-1}$ no período compreendido entre março e dezembro. Em Luziânia, GO, o Sistema Santa Fé foi implantado em áreas irrigadas por pivô central e a produção forrageira, com irrigação suplementar, foi suficiente para alimentar 8 animais ha ${ }^{-1}$, com estimativa de ganho de peso de aproximadamente $800 \mathrm{~g} \mathrm{animal}^{-1} \mathrm{dia}^{-1}$ (Cobucci et al., 2007).

Resultados como os apresentados por Cobucci et al. (2001) e Portela (2003), nas Figuras 1 e 2 são exemplos de possibilidades de implantação de pastagens de B.brizantha cv Marandu e de P.maximum cv. Mombaça, em plantio

Tabela 2 - Produtividade e taxas de retorno diretas obtidas nas unidades demonstrativas do Sistema Barreirão, implantadas em cinco safras agrícolas em diferentes municípios e Estados brasileiros

\begin{tabular}{|c|c|c|c|c|c|}
\hline Safraagrícola & Total de municípios & Estados abrangidos & Cultura consorciada ${ }^{1}$ & Prod.média $\left(\mathrm{kg} \mathrm{ha}^{-1}\right)$ & Taxa de retorno diretax (média $)^{2}$ \\
\hline $1990 / 91$ & 11 & GO & Arroz de terras altas & 2.000 & 1,27 \\
\hline $1991 / 92$ & 15 & GO/TO/MG/MT/DF & Arroz de terras altas & 2.250 & 1,09 \\
\hline $1992 / 93$ & 8 & GO/MG/MT & Arroz de terras altas & 1.850 & 0,96 \\
\hline \multirow[t]{3}{*}{$1993 / 94$} & 3 & GO & Milho & 3.990 & 1,06 \\
\hline & 23 & GO/MS/MG/SP & Arroz de terras altas & 1.800 & 0,83 \\
\hline & 16 & GO/MS/MG/SP/MT & Milho & 3.360 & 0,80 \\
\hline \multirow[t]{3}{*}{$1994 / 95$} & 6 & GO/SP/MS/MG & Arroz de terras altas & $\mathrm{na}^{3}$ & $\mathrm{na}^{3}$ \\
\hline & 10 & GO/SP/MS/PI & Milho & $\mathrm{na}^{3}$ & $\mathrm{na}^{3}$ \\
\hline & 1 & GO & Sorgo & 3.000 & 0,94 \\
\hline
\end{tabular}

\footnotetext{
${ }^{1}$ Gramíneas: Brachiaria brizantha, B. decumbens, Andropogon gayanus e Panicum maximum; Leguminosas: Calopogonium mucunoides e Stylosanthes sp

${ }^{2}$ Retorno por unidade monetária aplicada;

${ }^{3}$ Dados não-analisados.

Fonte: Yokoyama et al. (1998).
} 


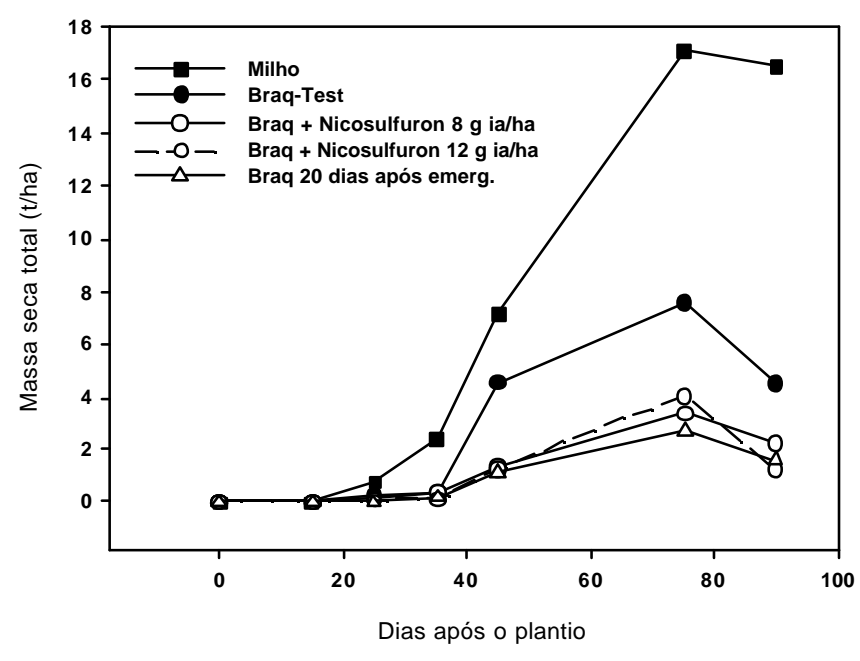

Figura 1 - Massa seca total do milho e do capim-marandu plantado solteiro, simultaneamente, e 20 dias após emergência do milho, com e sem herbicida. Fonte: Cobucci et al. (2001).

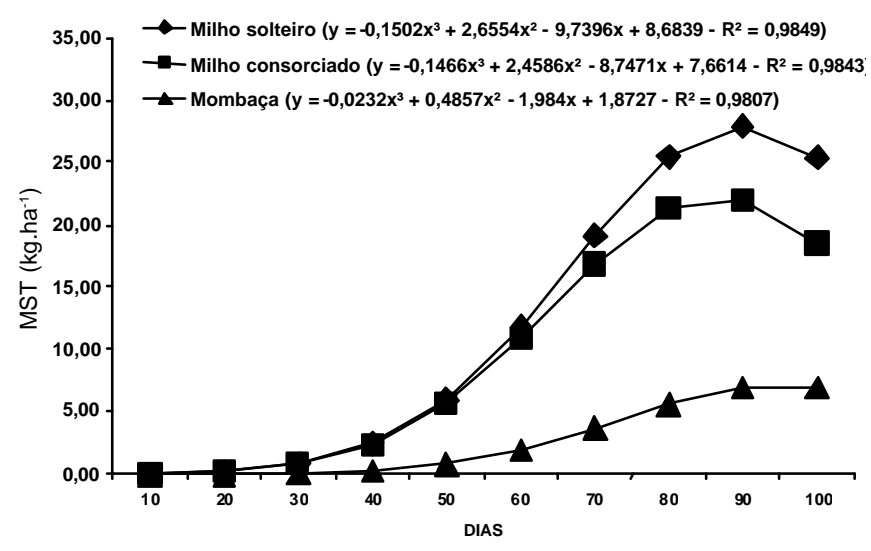

Figura 2 - Massa seca total do milho solteiro e consorciado e de forragem do capim-mombaça plantado solteiro em dias após plantio. Fonte: Portela (2003).

simultâneo com a cultura do milho, com grandes vantagens econômicas pela amortização dos custos com a comercialização dos grãos. No exemplo do capim-marandu, na Figura 1, após o plantio do milho com a braquiária, nos estádios inicias de crescimento da braquiária é aplicado um herbicida seletivo ao milho, em subdose para supressão parcial da braquiária. Esta tem seu crescimento retardado em favor da cultura do milho, que tem sua produção de grãos pouco afetada. A braquiária, por sua vez, embora tenha sua produção de massa diminuída, ainda consegue se estabelecer com um estande adequado de plantas, que cobre adequadamente o solo, e após a colheita do milho, tem sua implantação normalizada.

Kluthcouski \& Aidar (2003) comprovaram por meio de estudos de correlação, as vantagens do sistema, observando em 16 ensaios, que os resultados de sistemas consorciados e solteiros de milho são muito próximos, validando suas possibilidades de uso (Figura 3).

O plantio de milho safrinha, em fevereiro-março, consorciado com diferentes espécies forrageiras, nos Cerrados, é uma nova realidade com o uso de herbicidas supressores, que aliado ao plantio direto, tem auxiliado o processo de manutenção da produção das pastagens, a recuperação de pastagens degradadas ou em inicio de degradação. Uma vez recuperadas, as pastagens apresentam melhor valor nutritivo no outono-inverno, aliviando o efeito acentuado da estacionalidade. Outras culturas anuais também têm sido utilizadas no plantio simultâneo com gramíneas forrageiras, com bons resultados, tais como: sorgo forrageiro, o granífero, e o girassol.

Estudos nessa mesma linha de pesquisa, com aperfeiçoamento de plantio simultâneo de culturas anuaís e pastagens, objetivando ajustar a população de plantas de culturas anuais, como o milho, e o arranjo das linhas de forrageiras nas entrelinhas das culturas, dosagens de herbicidas, tais como: nicosulfuron + atrazine, análise de crescimento, etc., tem sido conduzidos por vários pesquisadores em diferentes Universidades e Instituições de Pesquisa, vide trabalhos de: Pantano (2003), Bernardes (2003), Domingues (2004), Jakelaitis et al. (2004, 2005, 2005A), Severino (2005), Freitas (2005), Ceccon et al. (2008).

Todos esses trabalhos enfatizam as amplas possibilidades do plantio simultâneo de culturas anuais e forrageiras, tanto no verão, como no período de safrinha (Ceccon \& Staut, 2007), abrindo amplas possibilidades para a adoção de SILPs.

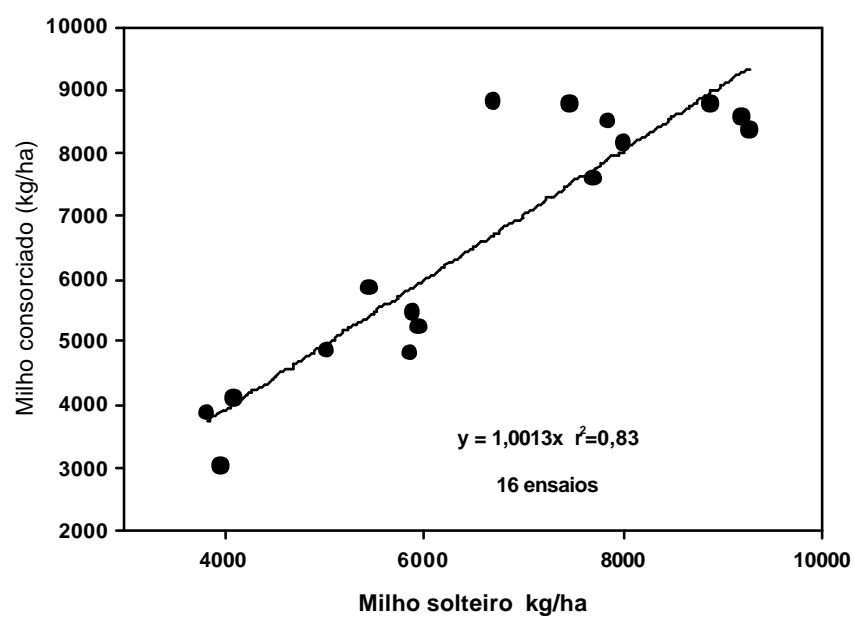

Figura 3 - Correlação entre produtividade do milho solteiro e consorciado em 16 ensaios conduzidos pela Embrapa Arroz e Feijão. Fonte: Kluthcouski \& Aidar (2003). 
SILPs e redução de pragas, doenças e plantas invasoras

Esta linha de pesquisa, embora com vários trabalhos já realizados e apresentados na literatura, ainda merece mais dedicação, pois é postulado que SILPs, principalmente quando planejados em rotações com diferentes cultivos anuais, alternando gramíneas com leguminosas, compostas e malváceas, por exemplo, com pastagens perenes em espaços de tempo mais longos, teriam importante papel na quebra de ciclos de pragas e doenças, e na diminuição da densidade de bancos ativos de sementes de ervas daninhas.

Observações efetuadas por Inomoto et al.(2007), a respeito da reação deBrachiaria spp, e Panicummaximum ao nematóide Pratylenchus, mostram uma reação diferenciada ao fator de reprodução e população por grama de raiz a esta praga de importância econômica para várias culturas (Tabela 3).

Estas observações de Inamoto et al. (2007) foram efetuadas no sentido de validar a informação de que algumas espécies de gramíneas forrageiras podem aumentar a população desse nematóide e causar sérios danos à cultura da soja e do milho. Nesse sentido, espécies mais suscetíveis e/ou hospedeiras devem ser substituídas por outras no esquema de rotação ou ficarem menos tempo no ciclo de cultivo.

Tabela 3 - Fator de reprodução (FR) e população final porgrama de raízes $(\mathrm{Nem} / \mathrm{g})$ de isolado de Pratylenchus brachyurus em Brachiaria spp (B) e Panicum maximum (PM), avaliados aos 118 dias após inoculação

\begin{tabular}{lcc}
\hline Espécie & \multicolumn{2}{c}{ P. brachyurus $-\mathrm{Pb}_{20}$} \\
\cline { 2 - 3 } & $\mathrm{FR}$ & Nem./g \\
\hline Soja & $10,69 \mathrm{a}$ & $198 \mathrm{a}$ \\
PM Tanzânia & $12,17 \mathrm{a}$ & $79 \mathrm{ab}$ \\
PM Mombaça & $7,07 \mathrm{ab}$ & $42 \mathrm{~b}$ \\
BB Mulato & $4,96 \mathrm{abc}$ & $31 \mathrm{bc}$ \\
BB Marandu & $3,50 \mathrm{bc}$ & $21 \mathrm{bcd}$ \\
B. humidicola & $2,20 \mathrm{~cd}$ & $6 \mathrm{ef}$ \\
B. decumbens & $1,79 \mathrm{~cd}$ & $9 \mathrm{def}$ \\
B. ruziziensis & $1,66 \mathrm{~cd}$ & $12 \mathrm{cde}$ \\
B. dyctioneura & $1,01 \mathrm{de}$ & $4 \mathrm{f}$ \\
Crotalaria spectabilis & $0,00 \mathrm{e}$ & $0 \mathrm{~g}$ \\
\hline
\end{tabular}

Médias seguidas pelas mesmas letras nas colunas não diferem pelo teste Tukey $(5 \%)$

Fonte: Adaptado de Inamoto et al. (2007).
Trabalho efetuado por Gorgen et al. (2008) demonstrou que o manejo da palhada de Brachiaria ruziziensis, no processo de rotação lavoura-pastagem, em conjunto com a inoculação por Trichoderma harzianum pode exercer controle efetivo do mofo-branco, causado pelo fungo Sclerotinia sclerotiorum, aliando a prática cultural com o controle biológico (Tabela 4).

Outro trabalho relacionado a doenças de solo, em sistemas de rotação lavoura-pastagem, é apresentado por Costa (2002), demonstrando o efeito positivo da palhada de B. ruziziensis e de B. brizanthacv. Marandu no controle de Fusarium solani, Rhizoctonia solani e Sclerotinia sclerotiorum (Tabela 5).

Em avaliação sobre banco de sementes de ervas daninhas em SILPs, Ikeda et al. (2007) observaram, em experimento de longa duração na Embrapa Cerrados, Planaltina, DF, que esses sistemas podem reduzir consideravelmente o banco de sementes quando comparados a sistemas contínuos de lavoura, sendo que o sistema convencional de preparo de solo, comparado ao SPD, apresenta maior densidade de sementes de plantas daninhas. A adubação de manutenção mostrou-se mais efetiva do que a adubação corretiva gradual, na diminuição do banco de sementes. (Tabela 6).

Nesse mesmo experimento, Ikeda et al. (2007 a) estudaram a estrutura da composição floristica, medindo, pelo índice de valor de importância de cada família encontrada no banco de sementes, o efeito dos SILPs e dos sistemas convencionais. Os autores verificaram que o sistema de cultivo (adubação de manutenção ou de correção gradual) e os sistemas de preparo do solo (convencional e direto), são muito importantes na determinação da estrutura floristica dos bancos de sementes. A adubação corretiva gradual (doses mais elevadas de calcário, gesso e adubos formulados) aumentou o número de famílias e de espécies presentes em relação à adubação de manutenção.

SILPs e a qualidade do solo

A correlação entre SILPs e qualidade do solo, envolvendo as características químicas, físicas e biológicas do solo, é postulada como uma das maiores virtudes dos SILPs tendo em vista o seu grande impacto econômico e

Tabela 4 - Porcentagem de escleródios mortos, parasitados por Trichoderma spp, e por outros fungos, em solo coberto ou não por B. ruziziensis, com ou sem aplicação de Trichoderma '1306', Jataí, Santo Antônio de Goiás, 2006

\begin{tabular}{|c|c|c|c|c|}
\hline Manejo & Escleródios mortos (\%) & Parasitismo Trichoderma spp (\%) & Parasitismo outros fungos(\%) & $\begin{array}{c}\text { Apotécios } / \mathrm{m}^{2} \text { formados } \\
\text { em campo }\end{array}$ \\
\hline Sem braquiária & $41,9 \mathrm{~b}$ & $44,7 \mathrm{~b}$ & $22,6 \mathrm{a}$ & $18,2 \mathrm{a}$ \\
\hline Com braquiária & $80,1 \mathrm{a}$ & $97,1 \mathrm{a}$ & $19,1 \mathrm{a}$ & $2,0 \mathrm{~b}$ \\
\hline
\end{tabular}

Médias seguidas pelas mesmas letras nas colunas não diferem pelo teste Tukey $5 \%$.

Fonte: Gorgen et al. (2008). 
Tabela 5 - Efeito da rotação de culturas e do uso de braquiária sobre a atividade microbiológica e patógenos do feijoeiro habitantes do solo

\begin{tabular}{lcccc}
\hline Rotação & Atividade biológica $\left(\mu\right.$ FDA $\left.\min ^{1} \mathrm{~g}^{1}\right)$ & Fusarium solani $(\mathrm{ppg})$ & Rhizoctonia solani $(\mathrm{ppg})$ & ${\text { Sclerotinia sclerotiorum }\left(\mathrm{escl} . \mathrm{m}^{3}\right)}$ \\
\hline Arroz & 0,46 & 1.120 & 83 & 0 \\
Milho & 0,55 & 2.720 & 42 & 0 \\
B. ruziziensis & 0,45 & 1.560 & 28 & 0 \\
B. brizantha & 0,50 & 1.340 & 24 & 0 \\
Soja & 0,29 & 3.160 & 32 & 3 \\
\hline
\end{tabular}

Fonte: Costa (2002).

Tabela 6 - Média de sementes de diferentes espécies de plantas invasoras encontradas em avaliação de banco de sementes em experimento de SILPs, profundidade de $0-20 \mathrm{~cm}$, Planaltina, DF

\begin{tabular}{|c|c|c|c|c|c|c|c|}
\hline \multicolumn{8}{|c|}{ Sistema } \\
\hline $\mathrm{LC}$ & LD & LPLC1 & LPCLC2 & LPLD & PLPC1 & PLPC2 & $\mathrm{PC} 2$ \\
\hline \multicolumn{8}{|c|}{ Sementes $\left(\mathrm{m}^{2}\right)$} \\
\hline 22.747 & 10.106 & 45.747 & 24.400 & 2.848 & 2.382 & 5.115 & 1.322 \\
\hline
\end{tabular}

L: lavoura contínua, LPL: lavoura-pastagem-lavoura; PLP: pastagem-lavoura-pastagem; P: pastagem contínua; C: preparo convencional do solo, D: semeadura direta; 1 : adubação de manutenção; 2 : adubação corretiva gradual.

Fonte: Adaptado de Ikeda et al. (2007).

ambiental. A hipótese principal favorável aos sistemas integrados e em rotação de lavoura-pecuária seria o efeito positivo das lavouras em elevar a fertilidade, amortizando os custos pela venda dos grãos, subprodutos, e a melhoria das propriedades físicas pela ação das raízes das forrageiras, que melhorariam a estrutura, elevariam os estoques de carbono, e a capacidade de infiltração e retenção de água no solo. Com a melhoria dessas qualidades haveria, também, um incremento na densidade e na riqueza da fauna do solo e outros atributos microbiológicos.

A Embrapa Gado de Corte vem desenvolvendo desde 1993/1994 um experimento de longa duração onde estão sendo estudados sistemas integrados e em rotação de lavoura e pecuária, comparados a sistemas contínuos de pecuária e lavoura. O objetivo é comparar a eficiência agronômica, e econômica, e avaliar a sustentabilidade da produção dos diferentes sistemas. Tem-se também, como objetivo, determinar alguns indicadores da qualidade do solo e da sustentabilidade (Macedo et al., 2001b).

É importante ressaltar que esse projeto foi implantado em uma área de pastagens degradadas de Brachiaria decumbens, as quais foram recuperadas ou renovadas por meio de diferentes tratamentos: adubação, calagem e tratos mecânicos; renovação com troca de espécies: Brachiaria brizantha e Panicum maximum, com plantio de soja ou milho, etc. de acordo com os diferentes tratamentos. Uma área de vegetação natural e uma área de pastagem degradada estão sendo mantidas como testemunhas para comparações.

Os tratamentos principais são constituídos por cinco sistemas de produção: S1- Pastagem Contínua; S2- Lavoura Contínua; S3- Pastagem 4 anos- Lavoura 4 anos; S4- Lavoura
4 anos - Pastagem 4 anos; S5- Lavoura 1 ano- Pastagem 3 anos (estabelecida no $2^{\circ}$ ano sem ou com lavoura de milho).

Estes sistemas são subdivididos em subsistemas que compreendem métodos de preparo de solo e sistemas de plantio: convencional e direto, cultivo de verão e de verão + inverno; adubação de manutenção de pastagens e cultivo consorciado ou não com leguminosas forrageiras, num total de 12 tratamentos.

Resultados de análise da fertilidade do solo, em sistemas tradicionais e em SILPs no decorrer do tempo, com relação ao fósforo disponível em Mehlich-1, são apresentados na Figura 4, e mostram que, embora sistemas contínuos de lavoura (LC) elevem consideravelmente os teores de P do solo, SILPs como: L4P4 e L1P3, também podem fazê-lo de forma econômica, principalmente com adubação de manutenção moderada das pastagens (esta prática não foi utilizada no exemplo apresentado).

Resultados de análises de algumas propriedades físicas do solo, estabilidade de agregados, resistência à penetração e taxa de infiltração de água, mostraram o grande papel das gramíneas forrageiras no melhoramento dessas propriedades. Pode-se observar que mesmo com apenas um ano de implantação da pastagem (1999), após 4 anos de lavouras, a estabilidade de agregados do solo (Figura 5) foi substancialmente incrementada pela ação do sistema radicular das gramíneas.

Em trabalho efetuado por Salton (2005), nesse experimento, em Campo Grande, MS, foram demonstrados os benefícios dos SILPs, com relação ao estoque de carbono e à agregação do solo. Fica evidente a importância das gramíneas forrageiras na rotação e do SPD, associados aos 


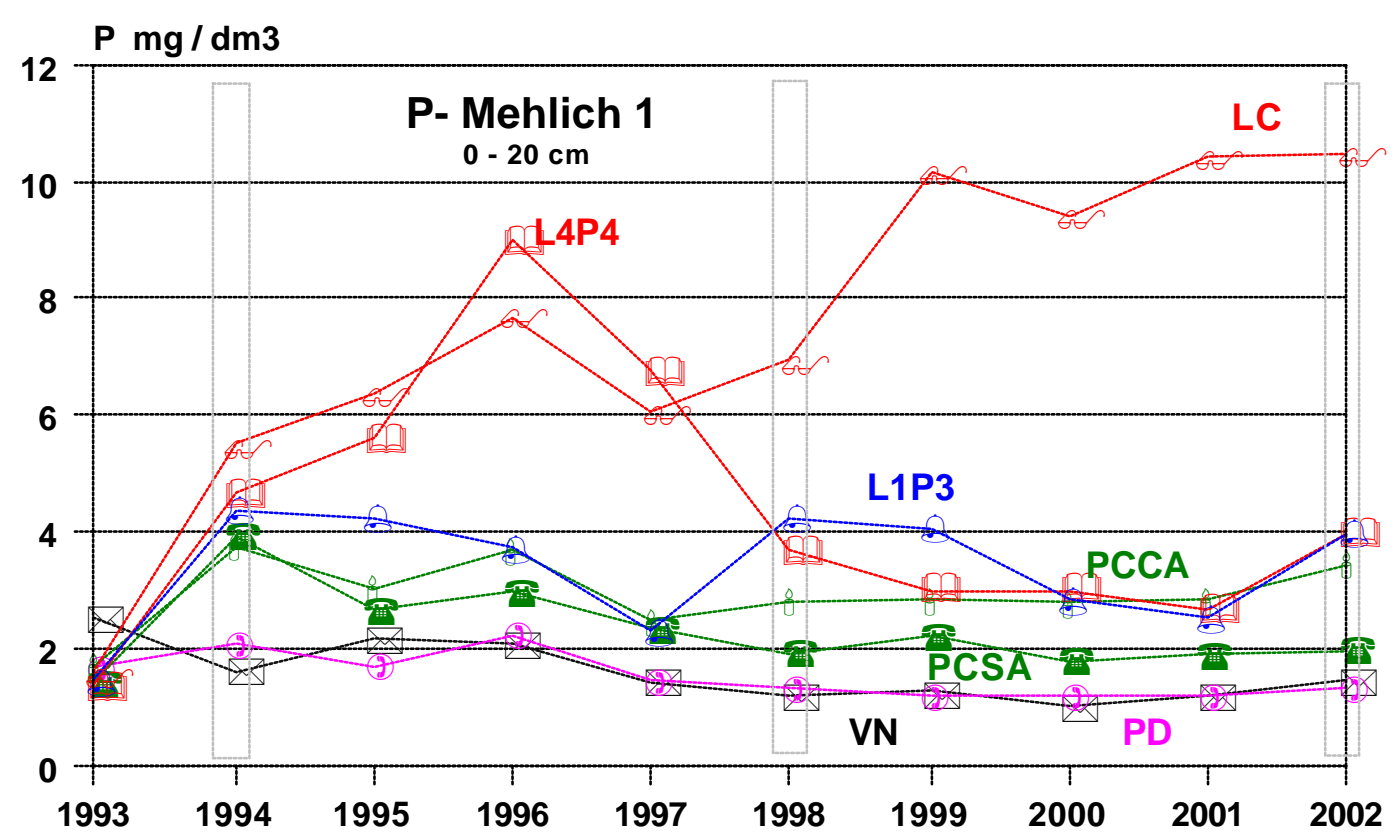

LC = lavoura contínua; L4P4 = SILP lav. 4 anos-pec 4 anos; L1P3 = SILP lav 1 ano-pec 3 anos; PCCA = past.contínua c/adub. manut.; $\mathrm{PCSA}=$ past.contínua s/ad.manut.; $\mathrm{VN}=$ veg.natural $; \mathrm{PD}=$ past.degradada .

Figura 4 - Dinâmica dos teores de P do solo (Mehlich-1) na camada de 0 a 20 cm, em sistemas convencionais e SILPs em um LV Distrófico, Campo Grande, MS. Fonte: Macedo (2005).

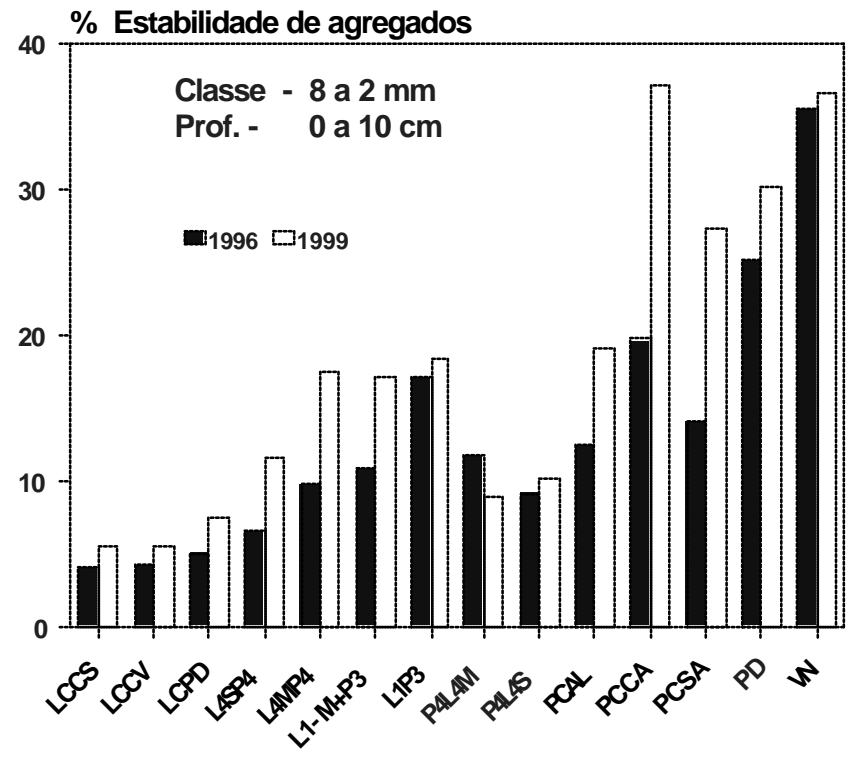

Figura 5 - Porcentagem de agregados de solo ( 8 a 2 mm de diâmetro) estáveis em água, na camada de 0 a $10 \mathrm{~cm}$ de profundidade em um LE, textura argilosa, sob diferentes manejos, em sistemas contínuos de pastagens e lavouras e de sistemas integrados de lavoura e pecuária, Campo Grande, MS. Fonte: José A. Bono \& Manuel Macedo, (dados não publicados).
SILPs, na região dos Cerrados (Tabela 7 e Figura 6). Os SILPs apresentam estoque em posição intermediária em relação à vegetação natural e as pastagens de uso contínuo, mas com manejo adequado de reposição de nutrientes e ajuste de lotação animal. Nessa ocasião, as pastagens com leguminosas implantadas em 1993/94, já possuíam um estoque de carbono superior à vegetação nativa (Tabela 7).

Em outro experimento de longa duração sobre SILPs, que está sendo realizado na Embrapa Cerrados (Vilela et al., 2001), Marchão (2007) efetuou estudos sobre as propriedades físicas do solo, estoque de carbono e a macrofauna, para avaliar a qualidade do solo dos SILPs comparados a sistemas tradicionais e contínuos de lavoura e pastagem, incluindo métodos de preparo de solo e sistema de plantio direto, com dois níveis de adubação de manutenção. Uma área de vegetação nativa foi tomada como referência. O mesmo constatou que os SILPs alteram alguns atributos físico-hídricos do solo, acarretando incremento na resistência a penetração e na densidade do solo pelo pisoteio dos animais durante a fase de pastagem na rotação, mas estes não foram fatores limitantes a produção dos cultivos anuais subsequientes. Os SILPs contribuem 
Tabela 7 - Estoque de carbono orgânico no solo de camadas de um LV em Campo Grande,MS, submetido a sistemas de manejo durante 11 anos. L-PC = lavouras em plantio convencional, L-PD = lavouras em plantio direto, S1P3 = rotação soja por 1 ano - pastagem (B. brizantha) por 3 anos, S4P4 = rotação soja por 4 anos - pastagem $(P$. maximum $)$ por 4 anos, $\mathrm{PP}=$ pastagem permanente (B. decumbens), $\mathrm{PP}+\mathrm{L}=$ pastagem permanente $($ B. decumbens) consorciada com leguminosas e $\mathrm{VN}=$ vegetação natural

\begin{tabular}{|c|c|c|c|c|c|c|c|}
\hline $\begin{array}{l}\text { Prof. } \\
(\mathrm{cm})\end{array}$ & L-PC & L-PD & S1P3 & $\begin{array}{l}\mathrm{S} 4 \mathrm{P} 4 \\
-\mathrm{Mg} \mathrm{ha}^{-}\end{array}$ & PP & $\mathrm{PP}+\mathrm{L}$ & $\mathrm{VN}$ \\
\hline 0 a 2,5 & $4,8 \mathrm{~d}$ & $6,2 \mathrm{~cd}$ & $7,8 \mathrm{c}$ & $7,2 \mathrm{c}$ & $6,6 \mathrm{c}$ & $12,0 \mathrm{a}$ & $10,0 \mathrm{~b}$ \\
\hline 2,5 a 5 & $5,1 \mathrm{~d}$ & $5,5 \mathrm{~cd}$ & $7,0 \mathrm{~b}$ & $6,2 \mathrm{bc}$ & $7,2 \mathrm{~b}$ & $8,7 \mathrm{a}$ & $6,7 \mathrm{~b}$ \\
\hline 5 a 10 & $13,5 \mathrm{abc}$ & $12,2 \mathrm{bc}$ & $12,8 \mathrm{abc}$ & $11,8 \mathrm{c}$ & $14,3 \mathrm{a}$ & $13,8 \mathrm{ab}$ & $13,6 \mathrm{abc}$ \\
\hline 10 a 20 & $23,0 \mathrm{a}$ & $23,5 \mathrm{a}$ & $22,9 \mathrm{a}$ & $22,7 \mathrm{a}$ & $25,4 \mathrm{a}$ & $24,1 \mathrm{a}$ & $23,7 \mathrm{a}$ \\
\hline 0 a 20 & $46,3 \mathrm{~d}$ & $47,4 \mathrm{~d}$ & $50,5 \mathrm{bcd}$ & $47,9 \mathrm{~cd}$ & $53,5 \mathrm{abc}$ & 58,6 a & $54,0 \mathrm{ab}$ \\
\hline
\end{tabular}

Valores médios de 3 repetições. Letras iguais indicam diferença inferior a DMS 5\% para a mesma camada.

Fonte: Salton (2005).

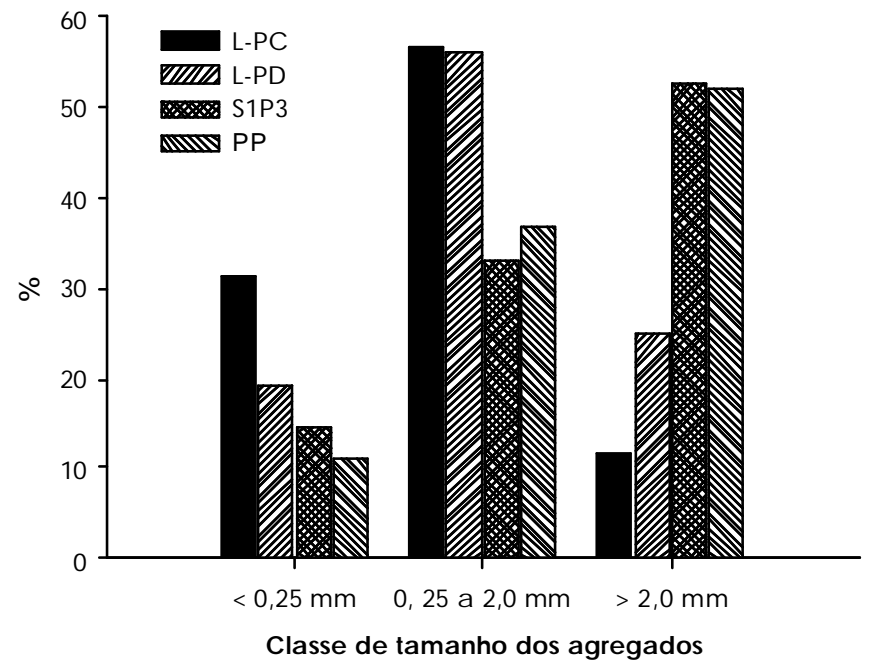

Figura 6 - Distribuição dos agregados da camada 0 a $5 \mathrm{~cm}$, agrupados em 3 classes de tamanho para os sistemas $\mathrm{L}-\mathrm{PC}=$ Lavouras em preparo convencional, $\mathrm{L}-\mathrm{PD}=$ lavouras em Plantio Direto, $\mathrm{S} 1 \mathrm{P} 3$ = rotação soja por 1 ano - pastagem (B. brizantha) por 3 anos, $\mathrm{PP}=$ pastagem permanente (B. decumbens), Fonte: Salton, 2005.

para aumentar o armazenamento de água e a porosidade do solo, sobretudo no SPD. Os sistemas de uso e preparo do solo influenciaram nos estoques de carbono e de nitrogênio, sobretudo no SPD, mas não se observou efeito de nível de fertilização. Em relação à macrofauna do solo os SILPs, baseados em SPD e na rotação com pastagens consorciadas com leguminosas, apresentaram maior densidade e biodiversidade de espécies, e, portanto, oferecem melhores condições para a sustentabilidade da qualidade do solo. Dentre as comunidades favorecidas pelo uso de SILPs destacam-se os gêneros Oligochaeta (minhocas) e Coleoptera (besouros coprófagos), que tem papel chave na estruturação do solo. A avaliação da macrofauna mostrou ser um bom indicador de qualidade do solo (Tabela 8).

Em outro estudo com as mesmas características, em um experimento de longa duração, também sobre avaliação de
SILPs, conduzido na Embrapa Agropecuária Oeste, Dourados, MS, Silva et al. (2008) obtiveram resultados similares, chegando à conclusão que os SILPs permitem a recomposição da comunidade da macrofauna invertebrada do solo após um período de dois anos de manejo, sugerindo que esse período já seria adequado para a rotação de SILPs, quanto a esse critério.

Com relação à interação entre atributos físicos e químicos do solo com a densidade e riqueza da macrofauna, Lourente et al. (2007) observaram em área de fazenda do MS, que já utiliza SILPs e SPD há vários anos, que não houve correlação entre densidade de indivíduos e atributos físicos do solo, mas esta mostrou-se influenciada por algumas propriedades químicas. Dentre estas correlações positivas destacam-se as existentes entre os teores de $\mathrm{P}$ no solo (Mehlich-1) e o gênero Oligochaeta (minhocas), e a de larvas de coleópteros com os teores de matéria orgânica.

SILPs e a economicidade na produção de graõs e animal

Alguns trabalhos disponíveis na literatura mostram as vantagens econômicas dos SILPs sobre os sistemas tradicionais contínuos: Costa \& Macedo (2001), Cobucci et al. (2007), Muniz (2007), Martha Jr. et al. (2008). A maioria apresenta vantagens nas taxas de investimento, do valor presente líquido dos SILPs sobre os demais.

Como exemplo é apresentado na Tabela 9, um estudo de caso descrito por Cobucci et al. (2007). Esta atividade com SILPs foi efetuada em 120 ha, em 3 glebas de 40 ha, e teve inicio no verão de 2005, com o plantio de soja em uma das áreas, e nas outras duas com o plantio simultâneo de milho+braquiária. O objetivo principal era o de ter pastagem produtiva no período de outono-inverno, entre maio e setembro, e concluir a engorda de animais.

Na Tabela 10, são apresentados resultados de ganho de peso animal, em experimento de longa duração da Embrapa Gado de Corte, onde estão sendo testados diferentes sistemas tradicionais e de SILPS, em um Latossolo da região do Cerrado. 
Tabela 8 - Densidade (indivíduos $/ \mathrm{m}^{2}$ ), riqueza de espécies (número de morfo espécies) da macrofauna de invertebrados em sistemas integrados de rotação lavoura-pecuária, sistemas contínuos e em vegetação natural de Cerrado, Planaltina, DF

\begin{tabular}{|c|c|c|}
\hline \multicolumn{2}{|l|}{ Sistemas de uso e preparo do solo } & Espécie \\
\hline Densi & de (ind./m²) & Riqueza $\left(n^{o}\right)$ \\
\hline Vegetação natural & 4.792 & 51 \\
\hline Pastagem contínua & 1.653 & 38 \\
\hline Lavoura contínua c/prep. solo & 501 & 4 \\
\hline Lavoura contínua s/prep. solo & 827 & 46 \\
\hline Pastagem - Lavoura c/prep. solo & 616 & 22 \\
\hline Pastagem - Lavoura s/prep. solo & 992 & 21 \\
\hline Lavoura-Pastagem c/prep. solo & 1.144 & 26 \\
\hline Lavoura-Pastagem s/prep. solo & 3.456 & 52 \\
\hline
\end{tabular}

Fonte: Adaptado de Marchão (2007).

Sistemas tradicionais de pastagem (PC), embora apresentem resposta à adubação de manutenção, quando comparados aos não adubados e à pastagem degradada, não apresentam a mesma eficiência econômica, segundo Costa et al (2001), se comparados aos SILPs (L1P3 e L4-P4). Às produções animais, nestes últimos, são adicionadas a venda de grãos das lavouras. Os efeitos indiretos, tais como melhoria das propriedades do solo, embora não computados, também são vantajosos para os SILPS.

\section{Inovações tecnólogicas e tendências dos SILPS}

De 1990 até a presente data, observou-se uma grande evolução no conhecimento do funcionamento dos SILPs, sobretudo nas práticas de plantio/cultivo de culturas anuais associadas com pastagens. Também se verificou a importância das rotações de culturas, da necessidade de uso de múltiplas espécies, que produzam resíduos mais ou menos recalcitrantes, que cubram melhor o solo, deixem mais palha para o SPD, distribuam seus sistemas radiculares: pivotantes e fasciculados, de forma alternada no tempo, mantenham ou aumentem os teores de carbono, e incrementem a densidade/riqueza macro e microbiológica.

Aspecto muito importante é o papel que as gramíneas tropicais, principalmente as braquiárias, desempenham na cobertura do solo, na produção de palha, no aumento do carbono, na estruturação do solo, de forma mais eficiente que os pastos anuais de milheto e de sorgo, por exemplo. $\mathrm{O}$ carbono incorporado ao solo por essas palhadas é melhor protegido se o sistema de plantio adotado nos SILPs for o do plantio direto, e se no processo de rotação for utilizado uma leguminosa forrageira. Em vários casos o estoque de carbono tem superado os da vegetação natural tomada como referência.
Existe, portanto, grande quantidade de resultados em plantio simultâneo de espécies, testando sistemas de preparo de solo, espaçamentos, arranjos de linhas, taxas de semeadura e, mais recentemente pesquisas avaliando a competição entre espécies, medida por taxa de crescimento das culturas, competição de nutrientes, etc (Campos, 2004; Severino et al., 2005; Lara-Cabezas \& Pádua, 2007; Cruz et al., 2008). Algumas áreas, no entanto, ainda estão relativamente descobertas, como os insetos-praga, doenças, nematóides, plantas daninhas, e suas interações com os SILPs.

Estudos de avaliação sócio-econômica precisam incorporar metodologias que considerem a contabilidade ambiental nos SILPs, pois estes são também alternativa para recuperação de áreas de pastagens degradadas, que somam porção extensa do território brasileiro. Sua adoção em maior escala ajudaria a evitar a abertura de novas áreas de fronteira, principalmente nas regiões do Cerrado e da Amazônia. A integração lavoura-pecuária permite a intensificação e o aumento da eficiência do uso da terra, proporcionando maiores produções, em menos tempo e em menor área, diminuindo inclusive as taxas de emissão de gases do efeito estufa por unidade de alimento produzido.

A nova tendência dos SILPs é a incorporação de árvores nos sistemas, configurando o que se chama de sistemas integrados de lavoura-pecuária-floresta (SILPFs). Trabalhos iniciais na Embrapa Gado de Leite, efetuados por Carvalho et al.(1997), onde o objetivo era ajustar forrageiras tropicais que melhor se adaptassem ao sombreamento em sistemas silvipastoris, tem evoluído para sistemas agrossilvipastoris, onde o arranjo das linhas de árvores já leva em consideração o espaço necessário para o plantio de culturas e seus tratos culturais (Soares et al., 2009).

A implantação de fábricas de papel e celulose em solos de baixa fertilidade, onde preponderava a pecuária de corte no nordeste do estado de Mato Grosso do Sul, e outras iniciativas no Paraná, em Minas Gerais, tem incentivado o plantio de árvores em fileiras duplas ou triplas, espaçadas de 8 a 14 metros, dependo do interesse do proprietário, aumentado a possibilidade de integração com a agricultura e a pecuária, e a diversificação de renda do produtor rural. Este pode proceder a um desbaste de madeira em duas etapas, um ao redor dos 7 anos e outro aos 14 anos, para fins de lenha, celulose, cercas,postes, etc., retirando parte ou todas as linhas externas, e anos mais tarde utilizar as árvores das linhas centrais para serraria e mobiliário.

As estatísticas sobre áreas utilizadas com SILPs são precárias, e não se tem a dimensão correta de sua extensão, estima-se que cerca de $5 \%$ da área de culturas anuais já pratique em algum grau essa tecnologia. Regiões no País que se destacam estão em Maracaju, MS; Rio Verde, GO; 
Tabela 9 - Produção animal e de grãos, e rendimentos econômicos de SILP implantado no ano agrícola 2005/06, Fazenda S.Luzia, São Raimundo das Mangabeiras, MA

\begin{tabular}{|c|c|c|c|c|c|c|c|c|}
\hline ANO 2007 & Área (ha) & Período (meses) & $\begin{array}{l}\text { Produtividade } \\
\left(@ / \mathrm{sc} \mathrm{ha}^{-1}\right)\end{array}$ & $\begin{array}{l}\text { Receita } \\
\left(\mathrm{R} \$ \mathrm{ha}^{-1}\right)\end{array}$ & $\begin{array}{c}\text { Custo } \\
\left(\mathrm{R} \$ \mathrm{ha}^{-1}\right)\end{array}$ & $\begin{array}{l}\text { Margem líquida } \\
\quad\left(\mathrm{R} \$ \mathrm{ha}^{-1}\right)\end{array}$ & $\begin{array}{c}\text { Margem líquida } \\
\text { Área }(\mathrm{R} \$)\end{array}$ & $\%$ \\
\hline Soja & 40 & 4 & $57 \mathrm{sc}$ & $1.368,20$ & $1.150,10$ & 218,10 & $8.724,00$ & 8,9 \\
\hline Terminação & 80 & 5 & 8,5@ & $1.983,33$ & $1.755,09$ & 233,33 & $18.666,40$ & 19,0 \\
\hline \multirow[t]{3}{*}{ Milho+ Braq. } & 80 & 4 & $143 \mathrm{sc}$ & $2.288,00$ & $1.400,00$ & 888,00 & $71.040,00$ & 72,2 \\
\hline & & & & & & Total & $98.430,40$ & 100 \\
\hline & & & & & & Total/ha/s & no $\mathrm{R} \$ 820,25$ & \\
\hline
\end{tabular}

Preço da @: R \$ 48,10; Preço do saco de soja: R\$24,00; Preço do saco de milho: R\$ 16,00.

Fonte: Cobucci et al.(2007).

Tabela 10 - Produção animal em sistemas tradicionais de pastejo contínuo, SILPs e pastagem degradada na região dos Cerrados, Campo Grande, MS

\begin{tabular}{|c|c|c|c|c|c|c|c|c|c|c|c|c|c|}
\hline \multirow[t]{2}{*}{ SISTEMAS } & \multicolumn{13}{|c|}{ ANOS } \\
\hline & $94 / 95$ & $95 / 96$ & 96/97 & $97 / 98$ & 98/99 & 99/00 & $00 / 01$ & $01 / 02$ & $02 / 03$ & 03/04 & $04 / 05$ & Total & Média \\
\hline & . & - & & SISTE & $\begin{array}{l}\text { IAS TH } \\
\text { B. dect }\end{array}$ & Imbens & $\begin{array}{l}\text { g/ha } \\
\text { ONAIS }\end{array}$ & --- & ---- & 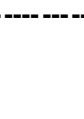 & --.--. & -a-n. & -----.- \\
\hline PCSA & 342 & 556 & 404 & 360 & 325 & 235 & 353 & 249 & 212 & 270 & 297 & 3603 & 328 \\
\hline PCCA & 385 & 497 & 379 & 497 & 464 & 278 & 358 & 289 & 267 & 340 & 432 & 4186 & 381 \\
\hline PCAL & 399 & 542 & 456 & 513 & 399 & 321 & 441 & 374 & 326 & 396 & 408 & 4575 & 416 \\
\hline
\end{tabular}

SISTEMAS INTEGRADOS LAVOURA-PECUÁRIA

Soja/sorgo -P. maximum Tanzânia

$\begin{array}{llllllllllllll}\text { L4-P4 } & - & - & - & - & - & 686 & 414 & 399 & - & 483 & 464 & 522 & \mathbf{2 9 6 8}\end{array}$

Soja/sorgo - Milho + B. brizantha Marandu

$\begin{array}{llllllllllllllll}\text { L1-P3 } & - & 842 & 522 & - & - & 358 & 393 & - & - & 484 & 486 & \mathbf{3 0 8 5} & \mathbf{5 1 4}\end{array}$

PASTAGEM DEGRADADA

B. decumbens

$\begin{array}{llllllllllllll}\text { PD } & 68 & 90 & 116 & 111 & 177 & 73 & 185 & 127 & 178 & 201 & 224 & \mathbf{1 5 5 0} & \mathbf{1 4 1}\end{array}$

PCSA = pasto contínuo sem adubação de manutenção; PCCA= pasto contínuo sem adubação de manutenção; PCAL= pasto contínuo sem adubação de manutenção; L4-P4= 4 anos de lavoura, seguidos de 4 anos de pastagem; L1-P3= 1 ano de lavoura seguido de 3 anos de pastagem implantada. com milho; PD= pastagem degradada. Fonte: Manuel et al., 2007.

Campo Mourão, PR ; Rondonópolis, MT, e iniciativas se destacam em Luis Eduardo Magalhães, BA; Uberlândia, MG; Pedro Afonso, TO; e Assis, SP.

\section{Literatura Citada}

ADAMOLI, J.; MACEDo, J.; AZEVEDo, J.G.; NETTO , J.M. Caracterização da região dos Cerrados. In: EMBRAPA/CPAC Solos dos Cerrados: tecnologias e estratégia de manejo. São Paulo: Nobel, 1986. p.33-74.

ANDRADE, R.P. Tecnologia de produção de sementes de espécies do genêro Brachiaria. In: SIMPÓSIO SOBRE MANEJO DA PAStAGEM, 11., 1994, Piracicaba. Anais... Piracicaba: Fundação de Estudos Agrários Luiz de Queiroz, 1994. p.49-71.

BERNARDES, L.F. Semeadura de capim braquiaria em pósemergência da cultura do milho para obtenção de cobertura morta em sistema de plantio direto. 2003. $42 \mathrm{f}$. Dissertação (Mestrado em Agronomia) - Faculdade de Ciências Agrárias e Veterinárias, UNESP, Jaboticabal. 2003
CAMPOS, A.X. Fertilização com sulfato de amônio na cultura do milho em um solo do Cerrado de Brasília sob pastagem de Brachiaria decumbens. 119p. 2004. Tese (Doutorado em Solos e Nutrição de Plantas) - Escola Superior de Agricultura Luiz de Queiroz, Universidade de São Paulo, Piracicaba. 2004

CARVALHO, M.M.; SILVA, J.L.O.; CAMPOS JR., B.A. Produção de matéria seca e composição mineral da forragem de seis gramíneas tropicais estabelecidas em um sub-bosque de angico-vermelho. Revista Brasileira de Zootecnia, v.26, n.2, p.213-218, 1997.

CECCON, G.; STAUT, L.A. Milho safrinha: rumo a estabilidade: anais. In: SEMINÁRIO NACIONAL DE MILHO SAFRINHA, 9., 2007, Dourados. Documentos... Dourados: Embrapa Agropecuária Oeste, 2007. 483p.

CECCON, G.; SACOMAn, A.; MATOSO, A.O. et al. Consórcio de milho safrinha com $B$. ruziziensis, em lavouras comerciais de agricultores em 2008. Dourados: Embrapa Agropecuária Oeste, 2008. 28p. (Boletim de Pesquisa, 48).

COSTA, F.P.; MACEDO, M.C.M. Economic evaluation of agropastoral systems: some alternatives for Central Brazil. In: WORKSHOP ON AGROPASTORAL SYSTEM IN SOUTH AMERICA, 2001, 
Japan. Proceedings... Japan: JIRCAS, 2001. p.57-62. (Working Report, 19).

COBUCCI, T.; KLUTHCOUSKI J.; AIDAR, H. Sistema Santa Fé: produção de forragem na entressafra. In: WORKSHOP INTERNACIONAL PROGRAMA DE INTEGRAÇÃO AGRICULTURA E PECUÁRIA PARA O DESENVOLVIMENTO SUSTENTÁVEL DAS SAVANAS TROPICAIS SULAMERICANAS, 2001, Santo Antonio de Goiás. Anais... Santo Antonio de Goiás: Embrapa Arroz e Feijão, 2001. p.125-135. (Documentos, 123).

COBUCCI, T.; WRUCH, F.J.; KLUTHCOUSKI, J. et al. Opções de integração lavoura-pecuária e alguns de seus aspectos econômicos. Informe Agropecuário, v.28, n.240, p.25-42, 2007.

RUZ, S.C.S.; PEREIRA, F.R.S.; BICUDO, S.J. et al. Nutrição do milho e da Bracharia decumbens cultivados em consorcio em difrentes preparos do solo. Acta Scientiarum.Agronomy, v.30, p.733-739, 2008 (supl.).

DENARDIN, J.E. Manejo adequado do solo para áreas motomecanizadas. In: SIMPÓSIO DE MANEJO DO SOLO E PLANTIO DIRETO NO BRASIL, 9., 1983, Passo Fundo. Anais... Passo Fundo: 1984. p.107-123.

DOMINGUES, L.A.S. Milho em plantio direto sobre Brachiaria brizantha no sistema integração agricultura-pecuária. 2004. 55f. Dissertação (Mestrado em Agronomia - Sistemas de Produção) - Faculdade de Engenharia de Ilha Solteira, UNESP, Ilha Solteira, 2004.

ELLIOT. B.R.; JARDINE, R. The influence of rotation systems on long term trends in wheat yield. Australian Journal of Agricultural Research, v.23, p.935-944, 1972.

FREITAS, F.C.L.; FERREIRA, F.A.; FERREIRA, L.R. et al. Cultivo consorciado de milho para silagem com Brachiaria brizantha no sistema de plantio convencional. Planta Daninha, v.23, n. 4, p.635-644, 2005.

GORGEN, C.A.; CIVARDI, E., PERRETO, E. et al. Controle de Sclerotinia sclerotiorum com o manejo de Brachiaria ruziziensis e aplicação de Trichoderma harzianum. Planaltina: Embrapa Cerrados, 2008. 3p. (Circular Técnica, 81).

GREENLAND, D.J. Changes in the nitrogen status and physical condition of soils under pastures, with special reference to the maintenance of the fertility of Australia soils used for growing wheat. Soils and Fertlizers, v.34, n.3, p. 237-251, 1971.

IKEDA, F.S.; MITJA, D.; VILELA, L. et al. Banco de sementes no solo em sistemas de cultivo lavoura-pastagem. Pesquisa Agropecuária Brasileira, v.42, n.11, p.1545-1551, 2007.

IKEDA, F.S., MITJA, D., CARMONA,R., VILELA, L. Caracterização floristica de bancos de sementes em sistemas de cultivo lavoura-pastagem. Planta Daninha, v.25, n.4, p.735$745,2007$.

INOMOTO, M.M.; MACHADO, A.C.Z.; ANTEDOMENICO, S.R. Reação de Brachiaria spp. e Panicum maximum a Pratylenchus brachyurus. Fitoplancton Brasilian, v.32, n.4, p.341-344. 2007.

JAKELAITIS, A.; SILVA, A.A.; FERREIRA, L.R. et al. Manejo de plantas daninhas no consórcio de milho com capim-braquiaria (Brachiaria decumbens). Planta Daninha, v.22, n.4, p.553560, 2004.

JAKELAITIS, A.; SILVA, A.F.; SILVA, A.A. et al. Influencia de herbicidas e de sistemas de semeadura em Brachiaria brizantha consorciada com milho. Planta Daninha, v.23, n.1, p.59-67, 2005.

JAKELAITIS, A.; SILVA, A.A., FERREIRA, L.R. et al. Efeito de herbicidas no consorcio de milho com Brachiaria brizantha. Planta Daninha, v.23, n.1, p.69-78, 2005.

KLUTHCOUSKI, J.; PACHECO, A.R.; TEIXEIRA, S.M. et al. Renovação de pastagens de Cerrado com arroz. 1. Sistema Barreirão. Goiânia: EMBRAPA-CNPAF, 1991. 20p. (Documentos, 33).

KLUTHCOUSKI J.; AIDAR, H. Implantação, condução e resultados obtidos com o sistema Santa Fé. In: _-_ Integração lavoura e pecuária. 1.ed. Santo Antonio de Goiás: Embrapa Arroz e Feijão, 2003. p.407-441.
LARA-CABEZAS, W.A.R.; PÁDUA, R.V. Eficiência e distribuição de nitrogênio aplicado em cobertura na cultura de milho consorciada com Brachiaria ruziziensis, cultivada no sistema Santa Fé. Bragantia, v.66, n.1, p131-140, 2007.

LOURENTE, E.R.P.; SILVA, R.F.; SILVA, D.A. et al. Macrofauna edáfica e sua interação com atributos químicos e físicos do solo sob diferentes sistemas de manejo. Acta Scientiarum Agronomic, v.29, n.1, p.17-22, 2007

MACEDO, M.C.M. Sustainability of pasture production in the savannas of tropical America. In: INTERNATIONAL GRASSLAND CONGRESS, 18., Winnipeg, Manitoba, Canada. Proceedings... Winnipeg, v.4, p.7-16.

MACEDO, M.C.M. Degradação de pastagens: conceitos e métodos de recuperação. In: SIMPÓSIO SUSTENTABILIDADE DA PECUÁRIA DE LEITE NO BRASIL. Anais... Juiz de Fora: Embrapa Gado de Leite, 1997. p.137-150.

MACEDO, M.C.M. Sistemas de produção animal em pasto nas savanas tropicais da América: limitações à sustentabilidade. In: REUNIÃO LATINOAMERICANA DE PRODUCCION ANIMAL, 16.; CONGRESO URUGUAYO DE PRODUCCION ANIMAL, 3., 2000, Montevidéu. Anales... Associación Latinoamericana de Produccion Animal, [2000]. (CD-ROM).

MACEDO, M.C.M. Integração lavoura e pecuária: alternativa para sustentabilidade da produção animal. In: SIMPÓSIO SOBRE MANEJO DA PASTAGEM - PLANEJAMENTO DE SISTEMAS DE PRODUÇÃO EM PASTAGENS, 18., 2001, Piracicaba. Anais... Piracicaba: FEALQ, 2001. p.257-283.

MACEDO, M.C.M. Degradação de pastagens: conceitos, alternativas e métodos de recuperação. Campo Grande: Embrapa Gado de Corte, 2001. 12p. (Curso de Pastagens).

MACEDO M.C.M.; ZIMMER, A.H. Implantação de pastagem de Brachiaria brizantha cv. Marandu em plantio simultâneo com milho em sucessão à soja em Mato Grosso do Sul. In: REUNIÃO ANUAL DA SOCIEDADE BRASILEIRA DE ZOOTECNIA, 27., 1990, Campinas. Anais... Campinas, 1990. p.290.

MACEDO, M.C.M.; ZIMMER, A.H. Sistema pasto-lavoura e seus efeitos na produtividade agropecuária. In: SIMPÓSIO SOBRE ECOSSISTEMA DE PASTAGENS, 2., 1993, Jaboticabal. Jaboticabal: FUNEP, UNESP, 1993. p.216-245.

MACEDO, M.C.M.; ZIMMER, A.H. Sistemas integrados de lavourapecuária na região dos Cerrados do Brasil. In: SIMPÓSIO INTERNACIONAL EM INTEGRAÇÃO LAVOURA-PECUÁRIA, 2007, Curitiba. Anais... Curitiba: UFPR, UFRGS, Ohio State University, 2007. 24p. (CD-ROM).

MACEDO, M.C.M.; BONO, J.A.; ZIMMER, A.H. et al. Preliminary results od agropastoral systems in the Cerrados of Mato Grosso do Sul - Brazil. In: WORKSHOP ON AGROPASTORAL SYSTEM IN SOUTH AMERICA, 2001, Japan. Proceedings... Japan: JIRCAS, 2001b. p.35-42. (Working Report, 19).

MARCHÃO, R.L. Integração lavoura-pecuária num Latossolo do Cerrado: impacto na física, matéria orgânica e macrofauna. 2007. 153f. Tese (Doutorado em Agronomia - Solo e Água) Escola de Agronomia e Engenharia de Alimentos, Universidade Federal de Goiás, Goiânia, 2007.

MARTHA JR, G.B.; VILELA, L.; SOUSA, D.M.G. Economia de fertilizantes na integração lavoura-pecuária no Cerrado. Revista de Política Agrícola, Ano XVII, n.4, p.14-19, 2008.

MENDES, M.L. O nematóide de cisto da soja (Heterodera glycine). In: Cultura da soja nos Cerrados. Piracicaba: POTAFOS, 1993. p.399-413.

MORON, A.; KIEHL, J.C. Dinâmica del fosforo en tres sistemas agricolas en el sudeste de Uruguay. Revista Ina. Inv., n.1, p.61-84, 1992.

MUNIZ, L.C. Avaliação bio-economica em sistema de integração lavoura-pecuária. 2007. 91f. Dissertação (Mestrado em Agronegócio - Desenvolvimento Sustentável) Escola de Agronomia e Engenharia de Alimentos, Universidade Federal de Goiás, Goiânia, 2007.

PANTANO, A.C. Semeadura de braquiaria em consorciação com milho em diferentes espaçamentos na integração 
agricultura-pecuária em plantio direto. 2003. 60f. Dissertação (Mestrado em Agronomia) - Faculdade de Engenharia, UNESP, Ilha Solteira, 2003.

PRECHAC, F.G. Propriedades fisicas y erosion in rotaciones de cultivos y pasturas. Revista Inia Inv., n.1, p.127-140, 1992.

ROSELLO, R. Devolucion del nitrogeno toral en rotacionaes com pasturas. Revista Inia Inv., n.1, p.27-35, 1992.

SALTON, J. Matéria orgânica e agregação do solo na rotação lavoura-pastagem em ambiente tropical. 2005. 155f. Tese (Doutorado em Agronomia, Ciências do Solo) - Universidade Federal do Rio Grande do Sul, Porto Alegre, 2005.

SANO, E.E.; BARCELLOS, A.; BEZERA, H.S. Assessing the spatial distribution of cultivated pastures in the Brazilian Savanna. Pasturas Tropicales, v.22, n.3, p.2-15, 2001.

SEVERINO, F.J.; CARVALHO, S.J.P.; CRISTOFFOLETI, P.J. Interferências mútuas entre a cultura do milho, espécies forrageiras e plantas daninhas em um sistema de consorcio. IImplicações sobre a cultura do milho. Planta Daninha, v.23, n.4, p.589-596, 2005.

SILVA, R.F.; AQUINO, A.M.; MERCANTE, F.M. et al. Macrofauna invertebrada do solo em sistema integrado de produção agropecuária no Cerrado. Acta Scientiarum Agronomy, v.30, supl., p.725-731, 2008.
SOARES, A.B.; SARTORI, L.R.; ADAMI, P.R. et al. Influência da luminosidade no comportamento de onze espécies forrageiras perenes de verão. Revista Brasileira de Zootecnia, v.38, n.3, p.443-451, 2009.

VILELA, L.; AYARZA, M.A.; MIRANDA, J.C.C. Agropastoral systems: activities developed by Cerrados Agricultural Reseach Center (Embrapa Cerrados). In: WORKSHOP ON AGROPASTORAL SYSTEM IN SOUTH AMERICA, 2001, Japan. Proccedings... JIRCAS, 2001. p.19-33. (Working Report, 19).

YORONORI, J.T.; CHARCHAR, M.J.D.; NASSER, L.C.B. et al. Doenças da soja e seu controle. In: _-_ Cultura da soja nos Cerrados. Piracicaba: POTAFOS, 1993. p.333-390.

WHITE, D.H.; ELLIOTT, B.R.; SHARKEY, M.J. et al. Efficiency of land-use systems involving crops and pastures. Journal Australian Institute Agricultural Science, p.21-27, 1978.

ZIMMER, A.H.; PIMENTEL, D.M.; VALLE, C.B. et al. Aspectos práticos ligados à formação de pastagens. Campo Grande: EMBRAPA/CNPGC, 1986. 42p. (Circular Técnica, 12).

ZIMMER, A. H.; MACEDO, M. C. M.; KICHEL, A. N., EUCLIDES, V.B.P. Sistemas integrados de producción agropastoril. In: GUIMARÃES, E.; SANZ, J.I.; RAO, I.M. et al. (Eds.) Sistemas agropastoriles en sabanas tropicales de América Latina. s.1.: CIAT, 1999. p.245-283. (Publicación CIAT, 313). 